\title{
DESAIN DAN IMPLEMENTASI PEMODELAN DATABASE INDUSTRI KECIL MENENGAH KOTA PALEMBANG
}

\author{
Firamon Syakti $^{1}$, Hutrianto ${ }^{2}$, Usman Ependi ${ }^{3}$ \\ ${ }^{1,2,3}$ Fakultas Ilmu Komputer, Universitas Bina Darma \\ Jl. Ahmad Yani No 3 Seberang Ulu I, Palembang - Indonesia 30264 \\ Telp. (0711) 515582 Fax. (0711) 515582 \\ e-mail: firamon.syakti@binadarma.ac.id ${ }^{1}$, hutrianto@binadarma.ac.id ${ }^{2}$, u.ependi@binadarma.ac.id ${ }^{3}$
}

\begin{abstract}
The focus of this research is to design and implement a small medium industry database for the Palembang City Government. The database needs of small and medium industries due to the unavailability of data quickly and accurately when it requires information by the Department of Industry in policy making. The design and implementation of the IKM database has stages carried out starting from the needs analysis, database formation, information modeling, dashboard manufacturing, to testing. The resulting dashboard can provide data in the form of graphs and tables relating to small and medium industries either through the criteria of the region or type of industry. The layout and presentation of the data has been validated using a heuristic evaluation approach involving three experts. The validation results show that all experts agree that the results of the design and implementation of small medium industry databases do not have usability problems as evidenced by the results of the average expert testing giving a value of 0 .
\end{abstract}

Keywords—Database, heuristic evaluation, industry, IKM

\begin{abstract}
ABSTRAK
Penelitian ini memiliki focus untuk melakukan desain dan implementasi database untuk industry kecil menengah (IKM) untuk Pemerintah Kota Palembang. Kebutuhan database industry kecil menengah (IKM) disebabkan tidak tersedianya data secara cepat dan akurat ketika membutuhkan informasi dalam menentukan pengambilan kebijakan bagi Dinas Perindustrian. Dalam melakukan desain dan implementasi database IKM memiliki tahapan yang dilakukan dimulai dari analisis kebutuhan, pembentukan database, pemodelan informasi, pembuatan dashboard, sampai dengan pengujian. Dashboard yang dihasilkan dapat memberikan data dalam bentuk grafik dan tabel berkaitan dengan IKM baik melalui kriteria wilayah mapun jenis industri. Bentuk dan penyajian data telah dilakukan validasi menggunakan pendekatan heuristic evaluation yang melibatkan tiga orang ahli. Hasil validasi menunjukkan bahwa semua ahli sependapat bahwa hasil desain dan implementasi database IKM tidak memiliki masalah usability yang dibuktikan dengan hasil pengujian rerata ahli memberikan nilai 0.
\end{abstract}

Kata Kunci- Database, heuristic evaluation, industry, IKM 


\section{Pendahuluan}

Pemerintah daerah merupakan perpanjangan tangan dari pemerintah pusat dalam melaksanakan kebijakan. Untuk itu keterediaan informasi berkaitan tupoksi menjadi keharusan agar pengambilan kebijakan tepat sasaran [1]. Salah satu hal mendasar dalam pengambilan kebijakan adalah akurasi data. Semakin baik data yang disajikan maka semakin akurat juga pengambilan kebijakan. Pemerintah daerah dalam melaksanakan fungsinya dibedakan berdasarkan jenis urusan. Urusan dalam pemrintahan terdiri dari urusan absolut, konkuren dan umum. Pemerintah daerah dalam hal ini Pemerintah Kota Palembang dalam melaksanakan urusan pemerintahan konkuren [2]. Urusan konkuren sendiri merupakan urusan pemerintahan yang dibagi dari pemerintah pusat, pemerintah daerah provinsi dan pemerintah daerah kabupaten/kota. Urusan pemerintahan konkuren sendiri telah masuk didalamnya pelaksanaan otonomi daerah.

Pemerintah Kota Palembang merupakan pemerintahan daerah tingkat II yang ada di Provinsi Sumatra Selatan. Pemerintah Kota Palembang memiliki dua puluh empat dinas. Salah satu dinas yang ada adalah Dinas Perindustrian yang mengurusi industri kecil menengah. Saat ini Dinas Perindustrian Kota Palembang mengalami kendala atau tidak maksimal dalam menentukan kebijakan yang disebabkan tidak tersedianya data yang memiliki nialai integritas yang tinggi. Kondisi tersebut disebabkan data yang tidak update, tidak memiliki visual, dan penyajian data yang lambat karena data yang disediakan dalam bentuk cetak dan sebagian data disimpan dalam arsip file excel [3]. Untuk itu perlu dilakukan instegrasi data sehingga data yang ada dapat divisual dan disajikan dengan cepat serta memiliki nilai integritas yang tinggi jika digunakan untuk pengambilan kebijakan.

Penyajian data industri kecil dan menengah dapat dilakukan secara sistematis dengan menggunakan database. Penggunaan database disebabkan kemampuan yang dimiliki dalam melakukan manajemen data. Database atau sering dikenal dengan basis data merupakan komponen penting dalam sistem informasi sebagai penyedia data. Selain itu juga database dapat berdiri sendiri dalam memberikan data (informasi) [4]. Database dibentuk berdasarkan representasi sebuah objek dalam bentuk angka, simbol atau huruf untuk memenuhi kebutuhan informasi [5]. Pengembangan sebuah database dapat dilakukan dengan cara sistematis yang dimulai dari desain konseptual, logikal 
sampai dengan implementasi pada sistem informasi [6]. Database juga dapat memberikan informasi secara visual dengan mudah kepada pengguna dengan alat bantu antarmuka sistem informasi [7].

Database telah dimanfaatkan diberbagai bidang seperti perbankan, industri maupun pemerintahan. Dalam dunia pemerintahan database menjadi tulang punggung sebagai penyuplai data untuk membantu pengambilan keputusan [8]. Kondisi tersebut dapat dilihat dari implementasi database pada kementrian dalam negeri untuk pembuatan kartu tanda penduduk [9] dan penggunaan database penduduk miskin sebagai alat bantu pengambilan kebijakan pengentasan kemiskinan [10].

Sesuai dengan uraian fakta yang telah dikemukakan pada Dinas Perindustrian Kota Palembang, maka perlu dibuat sebuah integrasi database industri kecil dan menengah sebagai acuan dalam pengambilan kebijakan bagi Pemerintah Kota Palembang khususnya dalam bidang perindustrian. Instegrasi database yang ditawarkan dibuat sesuai kebutuhan informasi yang dimulai dari desain dan pemodelan dan divisualisasi dalam bentuk dashboard sistem informasi industri kecil dan menengah Kota Palembang. Dengan demikian pihak Dinas Perindustrian dapat membuat kebijakan sesuai dengan data.

\section{Metode Penelitian}

Dalam melakukan desain dan pemodelan database industri kecil dan menengah pada Dinas Perindustrian Pemerintah Kota Palembang memiliki tahapan pengerjaan penelitian seperti yang diperlihatkan pada Gambar 1.

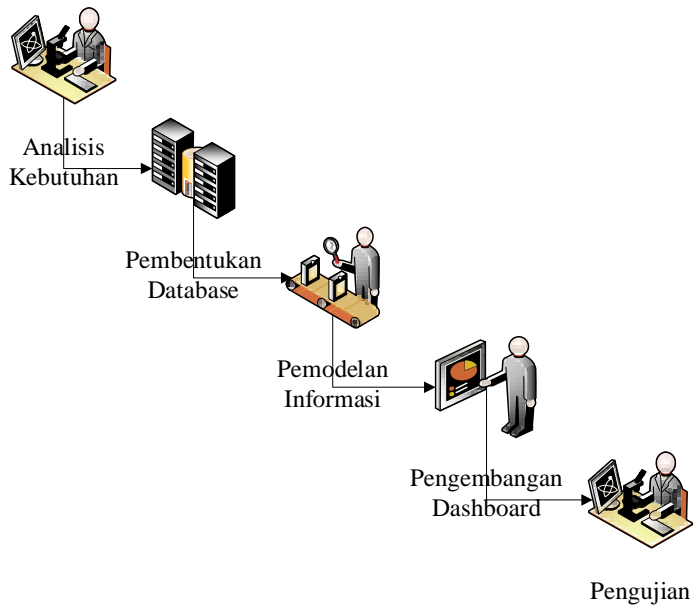

\section{Gambar 1. Tahapan penelitian}

Alur penelitian seperti yang diperlihat pada Gambar 1 dimulai dari proses analisis kebutuhan, pembentukan database, pemodelan informasi yang dibutuhkan, pengembangan dashboard informasi dan pengujian. Berikut dapat dijelaskan pekerjaan untuk masing-masing tahapan.

\section{a. Analisis Kebutuhan}

Analysis kebutuhan adalah proses penentuan kebutuhan bagi pengguna [11] Kebutuhan pemodelan informasi industri kecil menengah di Kota Palembang ini dibuat menggukan spesifikasi perangkat lunak dalam bentuk written document yang berisikan kebutuhan pengguna [12] 


\section{b. Pembentukan Database}

Pembentukan database merupakan proses pemodelan dan pembuatan database sebagai media penyimpanan [13] data industri kecil dan menengah yang ada di Kota Palembang. Pembentukan database dilakukan sesuai dengan kebutuhan informasi dari hasil analisis kebutuhan.

\section{c. Pemodelan Informasi}

Pemodelan informasi dilakukan menggunakan notasi unified medeling language (UML). UML memiliki kemampuan untuk membuat bluefrint dari sistem informasi yang akan dikembangkan. UML juga mampu memvisualisasikan, menentukan, mengkontruksi, dan mendokumentasikan system informasi [14]. UML sendiri memiliki tiga jenis diagram yaitu structure diagram, behavior diagram, dan interaction diagram. Structure diagram digunakan untuk memvisual keterkaitan [15], behavior diagram untuk memvisual perilaku [16] dan interaction diagram untuk memvisual interaksi pengguna ke sistem informasi [17].

\section{d. Pembuatan Dashboard Informasi}

Pembuatan dashboard informasi adalah proses penampilan informasi industri kecil dan menengah dalam bentuk grafik atau tabel agar data mudah untuk dibaca oleh pengguna. Penampilan informasi juga dilakukan sesuai dengan analisis kebutuhan yang dilakukan pada fase 1 .

\section{e. Pengujian}

Pengujian adalah proes akhir dalam melakukan desain dan pemodelan database industry kecil dan menengah pada Dinas Perindustrian Kota Palembang. Proses pengujian dilakukan menggunakan teknik heuristic yang melibatkan ahli.

\section{HASIL DAN PEMBAHASAN}

Sesuai dengan metode penelitian maka dapat hasil penelitian dan pembahasan dapat diuraikan sebagai berikut.

\section{a. Kebutuhan Pengguna}

Dalam melakukan desain dan pemodelan database industri kecil dan menengah kebutuhan pengguna dilihat dari kebutuhan informasi pada Dinas Perindustrian. Untuk itu sesuai dengan data industri kecil dan menengah yang terdapat data pada file excel kebutuhan pengguna dapat dijelaskan sebagai berikut yaitu: (1) Form penambahan dan pengelolaan data industri kecil dan menengah, (2) Import data industry kecil dan menengah, dan (3) Dashboard informasi industri kecil dan menengah yang dapat dilihat dari lokasi, jenis industri, dan wilayah yang dapat ditampilkan melalui grafik atau table. 


\section{b. Model Database}

Model database yang dibuat merupakan penterjemahan kebutuhan pengguna (Dinas Perindustrian). Pemodelan database yang dibuat menggunakan entity relationship diagram (ERD). ERD merupakan hubungan entitas-entitas dari objek untuk memvisualisasi hubungan tabel sebagai tempat penyimpanan data [18]. Terdapat empat entitas utama sebagai pembentuk atau penyedia data yang akan dijadikan informasi. Entitas tersebut yaitu entitas kelurahan, kecamatan, kategori IKM dan data IKM seperti yang diperlihatkan pada Gambar 2.

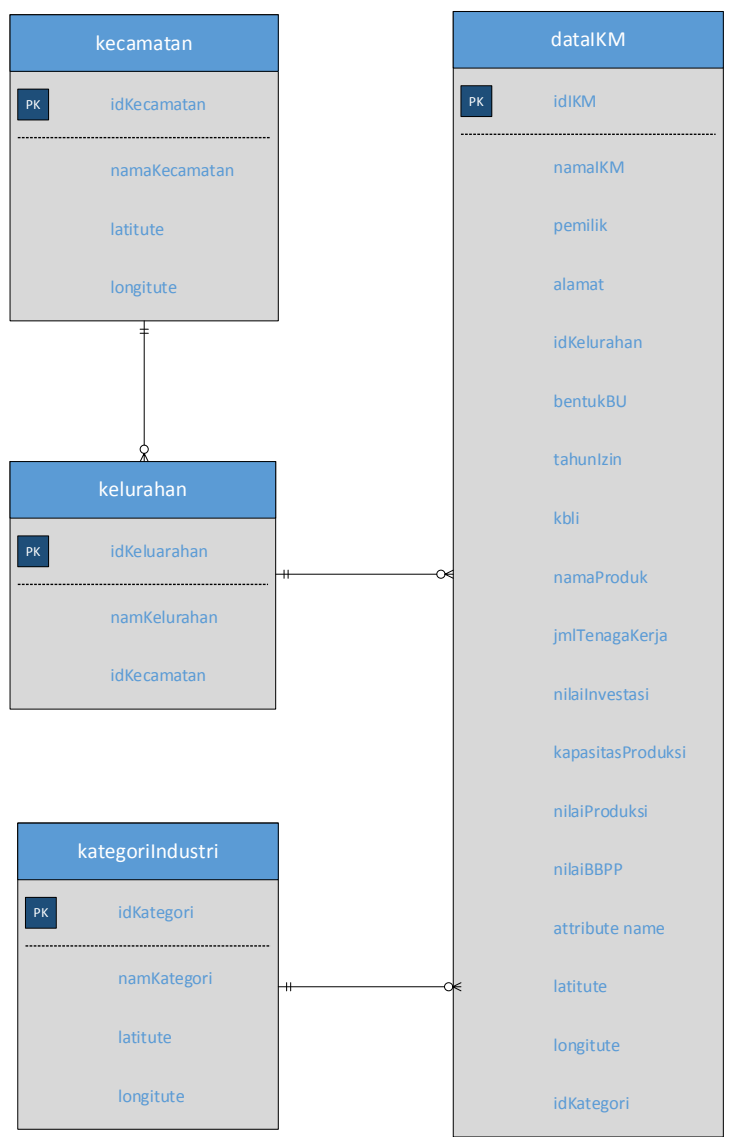

Gambar 2. Pemodelan Database

\section{c. Model Informasi}

Model informasi digunakan untuk menggambarkan bagaiama informasi yang ditampilan dan disediakan dalam mendukung pengambilan keputusan. Model informasi digambarkan menggunakan notasi $U M L$ kategori behavior diagram use case diagram seperti yang diperlihatkan pada Gambar 3.

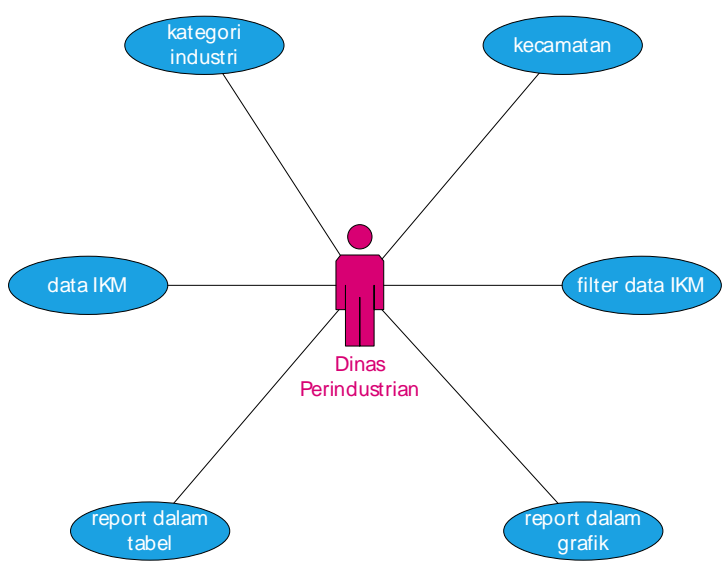

Gambar 3. Pemodelan Database

Dari Gambar 3 dapat diketahui bahwa akses yang diberikan merupakan akses tunggal bagi Dinas Perindustrian Kota Palembang. Informasi yang dapat dikelolah yaitu kategori industri, kecamatan, data IKM, filter data IKM dan report. Report teridiri dari grafik IKM kecamatan, grafik kategori industri, rekapitulasi indsutri, dan informasi Data IKM.

\section{d. Dashboard Informasi}

Sesuai dengan kebutuhan penggna dan pemodelan informasi serta pembentukan database maka berikut adalah dashboard informasi yang dihasilkan. Gamba 4 
merupakan halama nuja dashboard industri kecil dan menengah selah pengguna login. Dari halaman ini pengguna Dinas Perindustrian dapat melakukan aktifitas lain.

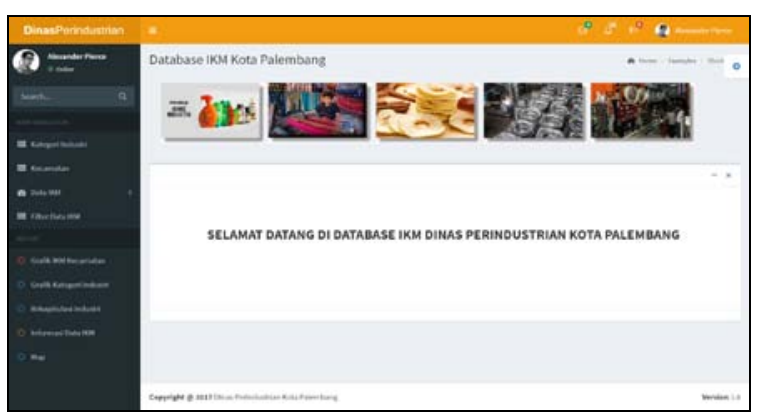

\section{Gambar 4. Halaman muka dashboard}

Untuk melakukan penambahan data pada database IKM dapat dilakukan dengan du acara yaitu melakukan import data sesuai format database IKM atau melakukan entri manual melalui form seperti yang diperlihatkan pada Gambar 5.

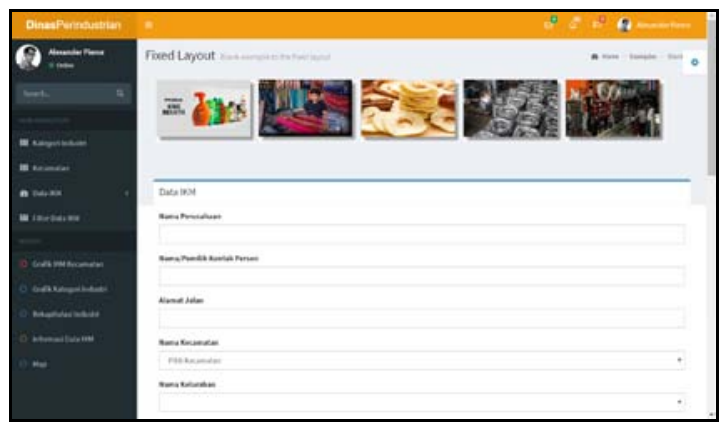

Gambar 5. Input data IKM

Database industri kecil dan memengah yang telah diimputkan ke database dapat diolah atau disajikan dalam bentuk laporan. Seperti yang diperlihatkan pada Gambar 6 merupakan laporan industri kecil dan memengah untuk setiap kecamatan yang ada di Kota Palembang.

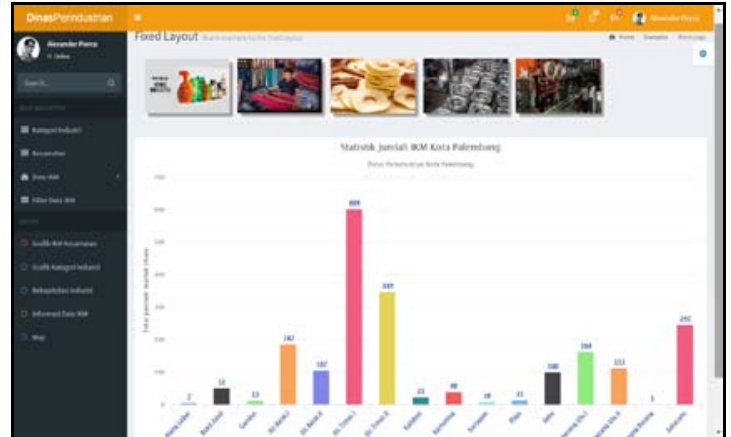

Gambar 6. Laporan IKM Kecamatan

Selain laporan industri kecil dan menengah yang dikelompokkan berdsarakan kecamatan dashboard industri kecil menengah juga dapat ditampilkan berdasrakan jenis atau kategori industri seperti yang diperlihatkan pada Gambar 7.

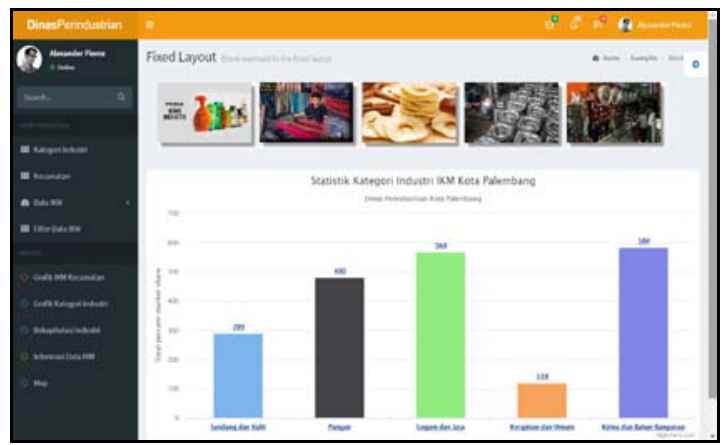

Gambar 7. Laporan IKM Kategori

Laporan industri kecil dan menengah juga dapat ditampilkan dalam bentuk tabel guna memudahkan pengguna dalam membaca data seperti yang diperlihatkan pada Gambar 8.

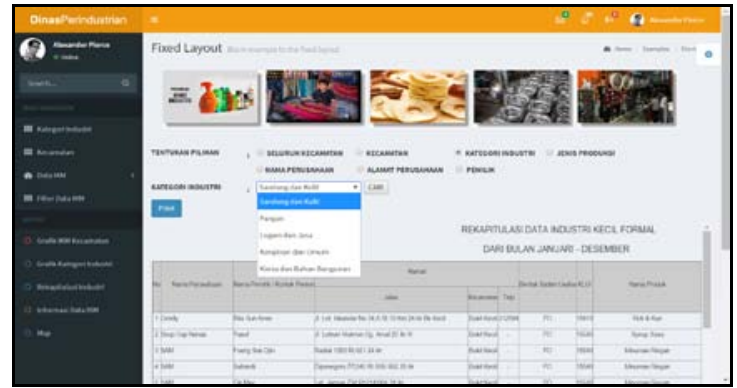

Gambar 8. Laporan IKM Dalam Tabel 
Dashboard informasi seperti yang diperlihatkan pada Gambar 4 sampai dengan Gambar 8 merupakan informasi hasil extraksi database industry kecil dan menengah. Data atau informasi yang ditampilkan dapat dengan mudah untuk dibaca sehingga pihak Dinas Perindustrian dapat dengan cepat apa yang harus dilakukan dalam penentuan kebijakan.

\section{e. Pengujian}

Pengujian adalah proses verifikasi atau validasi dari sebuah perangkat lunak atau produk. Didalam peneltian ini pengujian desain dan implementasi pemodelan database dilakukan menggunakan usability dengan pendekatan heuristic evaluation. Pengujian heuristic digunakan untuk melihat efektivitas, efesiensi dan mencapai kepuasan penggunaan bagi sebuah produk [19]. Dalam melakukan pengujian dengan heuristic evaluation penguji yang terlibat adalah ahli yang terdiri dari 3 sampai dengen 5 orang ahli dengan akhir penilaian 0 sampai dengan 4 , dan 0 adalah nilai terbaik [20]. Kriteria penilaian heuristic evaluation 0: tidak ada masalah usability, 1: cosmetic problem 2: minor, perbaikan diperlukan, 3: major, perlu ada perbaikan dan berpengaruh signifikan, 4: catastrophe, perlu desain ulang. Untuk itu pengujian dari implementasi databae industri kecil dan menengah Kota Palembang dapat dilihat pada Tabel 1.

Tabel 1. Hasil Pengujian

\begin{tabular}{|c|l|c|c|c|}
\hline No & \multicolumn{1}{|c|}{ Pernyataan } & Ahli 1 & Ahli 2 & Ahli 3 \\
\hline 1 & $\begin{array}{l}\text { Visibility of } \\
\text { system status }\end{array}$ & 0 & 0 & 0 \\
\hline 2 & $\begin{array}{l}\text { Match between } \\
\text { system and the } \\
\text { real world }\end{array}$ & 0 & 0 & 1 \\
\hline 3 & $\begin{array}{l}\text { User control } \\
\text { and freedom }\end{array}$ & 1 & 1 & 1 \\
\hline 4 & $\begin{array}{l}\text { Consistency and } \\
\text { standards }\end{array}$ & 0 & 1 & 1 \\
\hline 5 & Error prevention & 0 & 0 & 0 \\
\hline 6 & $\begin{array}{l}\text { Recognition } \\
\text { rather than recall }\end{array}$ & 0 & 1 & 0 \\
\hline 7 & $\begin{array}{l}\text { Flexibility and } \\
\text { efficiency of use }\end{array}$ & 0 & 0 & 0 \\
\hline 8 & $\begin{array}{l}\text { Aesthetic and } \\
\text { minimalist design }\end{array}$ & 1 & 1 & 1 \\
\hline 9 & $\begin{array}{l}\text { Help users } \\
\text { recognize, } \\
\text { diagnose, and } \\
\text { recover } \\
\text { from errors }\end{array}$ & 0 & 0 & 0 \\
\hline 10 & $\begin{array}{l}\text { Help and } \\
\text { documentation }\end{array}$ & 0 & 0 & 0 \\
\hline & \begin{tabular}{l} 
Rerata \\
\hline
\end{tabular} & 0.2 & 0.4 & 0.4 \\
\hline
\end{tabular}

Hasil pengujian seperti yang diperlihatkan pada Tabel 1 dapat diketahui bahwa ahli 1 memberikan nilai dengan rerata 0.2 , ahli 2 memberikan nilai dengan rerata 0.4 , dan ahli 3 juga memberikan nilai dengan rerata 0.4. Dari ketiga nilai yang diberikan oleh ahli maka dapat dikatakan bahwa dashboard informasi database industri kecil dan menengah mendapat nilai 0 atau tidak ada masalah.

\section{SiMPULAN}

Desain dan implementasi database industrri kecil dan menengah dapat menjadi alat dalam membuat kebijakan badi Dinas Perindustrian Kota Palembang. Informasi yang ditampilkan telah sesuai dengan kebutuhan Dinas Perindustrian yang dibuktikan dari kebutuhan pengguna 
dan dashboard informasi yang dihasilkan.

Selain itu juga antarmuka dashboard infromasi yang dibuat telah memenuhi standar usability sesuai hasil pengujian mendapatkan nilai rerata 0 oleh ahli.

\section{UCAPAN TERIMA KASIH}

Penulis mengucapkan terima kasih kepada Dinas Perindustrian Kota Palembang yang telah memberi akses data dan infromasi berkaitan dengan penelitian ini. Terima kasih juga kami sampaikan kepada Tim Jurnal Informatika yang telah bersedia meluangkan waktu untuk melakukan review dan menerbitkan artikel ini.

\section{DAFTAR PUSTAKA}

[1] Negara, K.S., UNDANG-UNDANG REPUBLIK INDONESIA NOMOR 23 TAHUN $2014 \quad$ TENTANG PEMERINTAHAN DAERAH, P.R. Indonesia, Editor. 2014, Indonesia: Jakarta.

[2] Rauf, R., HAKEKAT ORGANISASI PERANGKAT DAERAH (Suatu Tinjauan Teoritis dan Yuridis). Jurnal Kajian Pemerintahan, Politik dan Birokrasi, 2018. 3(2): p. 345-350.

[3] Toyib, M.H., Database IKM Dinas Perindustrian Kota Palembang. 2018, Dinas Perindustrian Kota Palembang.

[4] Mulyarto, A.R.I.P., Disain Sistem Basis Data Usaha Kecil dan Menengah (UKM) Agroindustri (Studi Kasus Pada UKM Tempe). Jurnal Teknologi Pertanian, 2012. 5(3).

[5] Putra, F.K., Disain Database Untuk Pengelolaan Data Kuliah Kerja Nyata (Kkn) Pada Institut Agama Islam
Negeri (Iain) Batusangkar. Jurnal SIMTIKA, 2019. 2(1): p. 60-65.

[6] Yudo, S., Pengembangan Database Pengelolaan Sumber Daya Air untuk Wilayah Kabupaten Pandeglang. Jurnal Air Indonesia, 2018. 7(1).

[7] Setiawan, N., Integrasi Database untuk Visualisasi dan Laporan pada Divisi Humas Universitas Swasta di Surabaya. Jurnal Titra, 2019. 7(1): p. 75-80.

[8] Latief, M., Pendekatan Database untuk Manajemen Data dalam Meningkatkan Kemampuan Mahasiswa Mengaplikasikan Konsep Basisdata. Prosiding APTEKINDO, 2012. 6(1).

[9] Sutanta, E. and A. Ashari, Pemanfaatan Database Kependudukan Terdistribusi pada Ragam Aplikasi Sistem Informasi di Pemerintah Kabupaten/Kota. Jurnal Sistem Informasi dan Teknik Informatika, 2012. 2(1).

[10]Ependi, U. DASHBOARD INFORMATION SYSTEM PENDUDUK MISKIN SEBAGAI BAHAN EVALUASI KEBIJAKAN PENGENTASAN KEMISKINAN. in Seminar Nasional Riset Inovatif. 2014.

[11]Ependi, U., Implementasi Model Scrum pada Sistem Informasi Seleksi Masuk Mahasiswa Politeknik Pariwisata Palembang. Jurnal Informatika: Jurnal Pengembangan IT, 2018. 3(1): p. 49-55.

[12]Ependi, U., Pemodelan Sistem Informasi Monitoring Inventory Sekretariat Daerah Kabupaten Musi Banyuasin. KLIK-KUMPULAN JURNAL ILMU KOMPUTER, 2018. 5(1): p. 49-60.

[13]Ependi, U., Mobile Application Monitoring Pengisian Uang Anjungan Tunai Mandiri PT Bank Mandiri Cabang Palembang. Jurnal Edukasi dan Penelitian Informatika (JEPIN), 2017. 3(1): p. 33-39. 
[14] Sulistiyah, S., R. Hidayat, and H. Haryanto, SISTEM INFORMASI PENERIMAAN KARYAWAN BERBASIS WEB PADA PT. SINAR SOSROTANGERANG. Jurnal Akrab Juara, 2019. 4(1): p. 33-40.

[15] Fakhroutdinov, K., Classification of UML 2.5 Diagrams. 2009, New Jersey: GLobal Logic.

[16] Shalahuddin, R.A.M., Rekayasa Perangkat Lunak Terstruktur dan Berorientasi Objek. 2013, Bandung: Informatika.

[17]Hayat, A., et al., Prototipe Sistem Informasi Persediaan Barang Logistik Berbasis Web Dengan Pemodelan $U M L$, in Proceedings Konferensi Nasional Sistem dan Informatika. 2015, STIKOM Bali.

[18] Putra, M.B.R. and B.T. Sartana, IMPLEMENTASI ELECTRONIC CUSTOMER RELATIONSHIP MANAGEMENT UNTUK MENINGKATKAN HUBUNGAN BAIK ORANG TUA SISWA (STUDI KASUS SMP AL-BAYAN ISLAMIC SCHOOL). InDonEsiA journaL Information System, 2018. 1(3): p. 210-216.

[19] Ependi, U., HEURISTIC EVALUATION FOR MOBILE APPLICATION (STUDI KASUS: APLIKASI DEPO AUTO 2000 TANJUNG API API PALEMBANG). Simetris: Jurnal Teknik Mesin, Elektro dan Ilmu Komputer, 2017. 8(2): p. 563-570.

[20]Ependi, U., T.B. Kurniawan, and F. Panjaitan, SYSTEM USABILITY SCALE VS HEURISTIC EVALUATION: A REVIEW. Simetris: Jurnal Teknik Mesin, Elektro dan Ilmu Komputer, 2019. 10(1)

[21] Fitria-, Muhammad Fauzan azima, Sulyono-,Teknologi Informasi E Complaint Pada Perguruan Tinggi, Jurnal Informatika Vol 18. No 2 (2018) pp 116 - 123. 